\title{
14 Comparing Land-use Planning Approaches in the Coastal Mekong Delta of Vietnam
}

\author{
N.H. Trung, ${ }^{1}$ L.Q. Tri, ${ }^{2}$ M.E.F. van Mensvoort ${ }^{3}$ and A.K. Bregt ${ }^{4}$ \\ ${ }^{1}$ College of Technology, Can Tho University, Can Tho City, Vietnam, e-mail: \\ nhtrung@ctu.edu.vn \\ ${ }^{2}$ College of Agriculture, Can Tho University, Can Tho City, Vietnam \\ ${ }^{3}$ Laboratory of Soil Science and Geology, Wageningen University, Wageningen, The \\ Netherlands \\ ${ }^{4}$ Center for Geo-Information, Wageningen University, Wageningen, The Netherlands.
}

\begin{abstract}
This chapter presents the application and comparison of three land-use planning (LUP) approaches in the coastal area of the Mekong Delta (MD), Vietnam. The land use of the studied area is diverse, quickly shifting and strongly contrasting. The contrast is not only in terms of resources but also in economic profitability and environmental sustainability. We wanted to use LUP approaches representing various levels of complexity and computation intensity, from empirical and qualitative to mechanistic and quantitative. From the variety of methods available, we selected a participatory LUP (PLUP) methodology, the guidelines for LUP by FAO enhanced with multi-criteria evaluation (FAO-MCE) and the land-use planning and analysis system (LUPAS) using interactive, multiple-goal linear programming. We used the same planning goal, worked in the same study area and the same period and produced three land-use plans. We compared the credibility, which is the technical and scientific appropriateness of the approach, and the stakeholder acceptability, which is the perception of the stakeholders of its practical value. The LUPAS map was best appreciated by stakeholders, but it also was the most expensive method. When comparing land-use plans of 2003 with actual land use of 2004, the PLUP map, which is disagreed with most strongly by the scientists, agrees best with the actual land use by the farmers. In the dynamic and contrasting land-use systems of the coastal MD, PLUP seems the most suitable approach for short-term advice, but for longer-term planning a combination of methods will probably work best.
\end{abstract}

\section{Introduction}

In the period 1975-1986, Vietnam had a centrally planned economy decreed by 5-year plans with production targets. In the southern part of the country, every province operated a number of large-scale state communal farms. These farms produced industrial crops such as sugarcane or pineapples but also rice or, in the coastal zone, shrimp. Private farmers had to sell predetermined quantities of rice for fixed prices to the government. Land use was planned by local and provincial authorities, guided by the Ministry of Planning and Investment (MPI) and supported by the National Institute for 


\section{Agricultural Planning and Projection} (NIAPP)

In 1986, economic liberalization was accomplished through the Vietnamese doi moi (renovation) policy. State farms were reformed and became cooperatives, where land-use decisions were left to the farmers. Private farmers negotiated long-term lease contracts for land-use rights with the local authorities and were free to decide about land use themselves. These changes had consequences for the role of NIAPP and MPI: from top-down centralized planning agencies they became advisers in land-use planning.

The FAO Framework for Land Evaluation was used most widely as a methodology for land-use advice. Mekong Delta-wide studies and studies at the district level were carried out. Some studies were a purely biophysical assessment of crop growth possibilities, others were enhanced with economic data on the evaluated land-use systems. The FAO method was also the basis for the NIAPP land-use planning study of Vinh Loi District (NIAPP, 1999). The strongly contrasting land-use types (extensive and intensive shrimp, mangrove forestry, double or single rice), with often unknown or hard-to-determine requirements (saltwater versus freshwater, tidal movement, growth conditions of mangrove trees), made a reliable assessment difficult. The approach was rather top-down, with limited interdisciplinary interaction and weak communication among stakeholders. This resulted in conflicting interests between stakeholders (Hoanh, 1996). Other problems also surfaced, such as the environmental effects and unreliability of shrimp cultivation and the acceptance of proposed land uses by the local people. Therefore, to ensure a more sustainable development, it is essential to introduce a land-use planning approach that can overcome these problems and better support the land-users and other stakeholders in the coastal area of the Mekong Delta (MD).

A multitude of recent land-use analysis and planning methods is available, for example, the land-use planning (LUP) guidelines by FAO (1993), the participatory land-use planning (PLUP) methodology (Amler et al., 1999), the conversion of land use and its effects (CLUE) of Veldkamp and Fresco (1996), the trade-off model (Stoorvogel, 2001) and the land-use planning and analysis system (LUPAS) described by Hoanh et al. (2000), van Ittersum et al. (2004) and Roetter et al. (2005). They vary in degree of complexity from empirical to mechanistic, and in degree of computation from qualitative to quantitative. We believe that the methods can be grouped into: (i) participatory qualitative empirical methods using farmer and expert knowledge such as PLUP; (ii) semiquantitative and mechanistic methods such as the FAO guidelines; and (iii) quantitative and computational methods such as CLUE (based on regression) or LUPAS (based on multiple-goal programming).

It is hard to choose a 'most suited' method for the coastal MD. Each method is developed for a certain purpose or covers only a part of the land-use planning sequence set out by FAO (1993), but all methods are developed to advise on land use. Instead of choosing one single method, we decided to select three different approaches, apply them to the same study area and try to recognize the pros and cons of each approach. We used approaches with a different level of complexity and computation intensity, we compared the approaches in credibility (the technical and scientific appropriateness) and acceptability (the perception of the stakeholders on their practical value) and we hoped to come to an objective judgement for application in the coastal MD.

\section{The Study Area}

This study was carried out in an area of approximately 10,700 ha in two coastal villages of the MD: Vinh My and Vinh Thinh (Fig. 14.1). The study area has contrasting degrees of saltwater intrusion and land-use systems. Most of the area is now (2005) used for shrimp cultivation. There are two cultivation techniques in these villages: improved extensive and semi-intensive, with a difference in level of applied technology, feeding strategy, recruitment system (natural recruitment for improved extensive or stocking 
with larvae from hatcheries for semi-intensive), stocking density and use of chemical inputs. The risks involved in shrimp cultivation come from shrimp disease, water pollution, lack of technology and capital, bad farm management and the quality of shrimp larvae (Kempen, 2004).

There is a thin strip of strongly exploited mangrove forests along the coast. Farmers practice the government-controlled forestshrimp system. Behind the mangrove zone, salt production occurs, sometimes in combination with shrimp. Rainfed rice can still be found in the northern and central part of the area. Most farmers can grow only one highyielding variety per year in the wet season because salinity intrusion in the dry season inhibits a second crop. Sometimes the single rice crop is combined with vegetables in the dry season, but this is limited to areas where fresh groundwater is available for irrigation. Combined rice-shrimp systems were also expected, but no farmers were practising the rice part of this system during the rainy season of 2003 because there had not been enough rainfall to flush the accumulated salts from the soil at the beginning of the rainy season (Kempen, 2004).
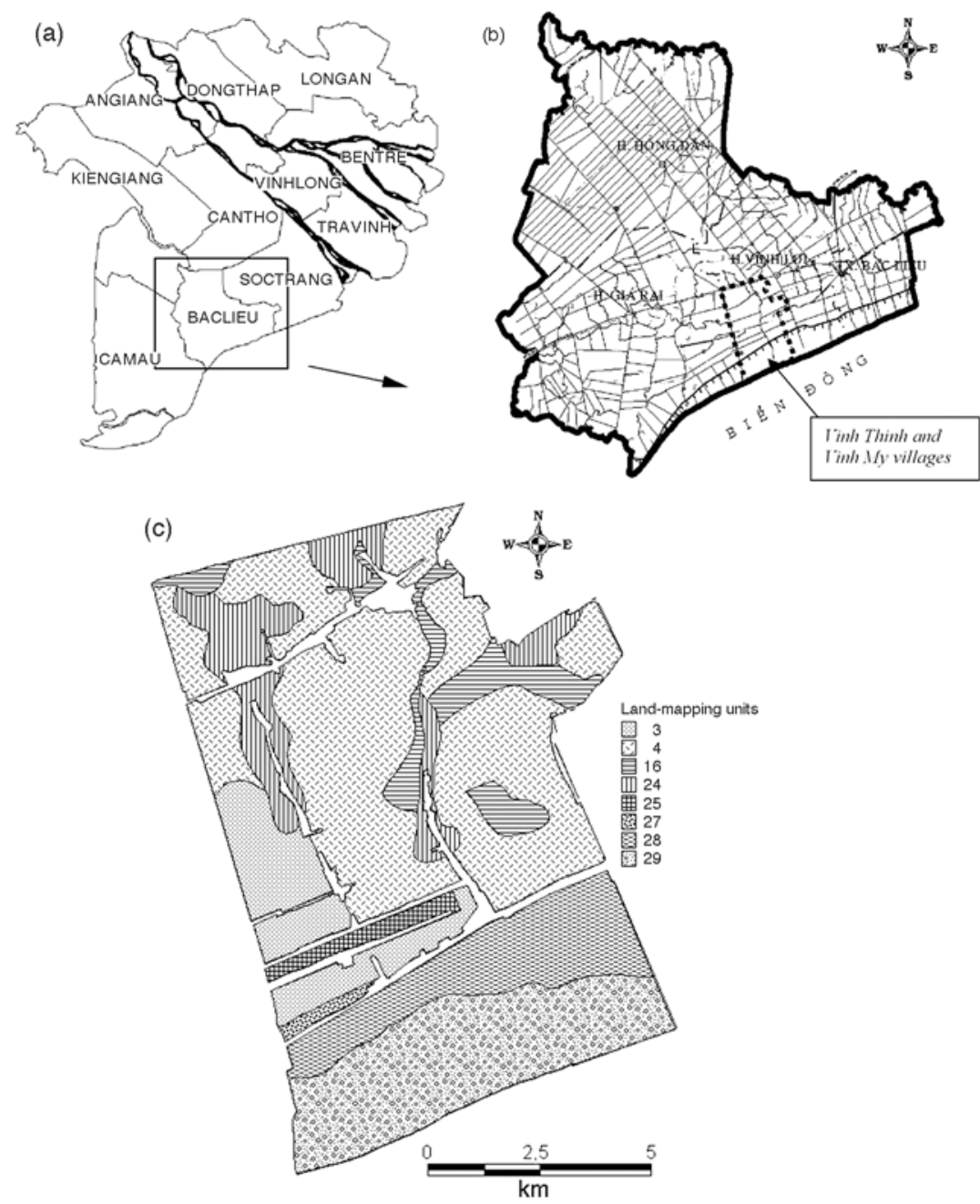

Fig. 14.1. The study area and its land unit map (from NIAPP, 1999). 
Four soil types are found (NIAPP, 1999). More than half of the area (5025 ha) has nonacid or weak-acid alluvial soils, which are slightly saline in the dry season. Severe acid sulphate soils (ASS), which are strongly saline in the dry season, can be found along the coast (3134 ha). These soils extend approximately $4 \mathrm{~km}$ land-inward. The remaining two soil types, found further inland, are weakly ASS (685 ha) and severe ASS (968 ha), both with moderate salinity in the dry season. NIAPP did not clearly define the degree of salinity (Kempen, 2004).

\section{Methodology}

The study has been carried out in four steps: (i) review and select LUP approaches for the study; (ii) apply the selected LUP approaches in the studied area; (iii) compare the credibility and acceptability of the LUP approaches; and (iv) discuss a proper LUP approach for the coastal areas of the MD.

We took the most widely used methodology (FAO-MCE) as a starting point. We wanted methods of different levels of complexity and computation intensity, so we also used a participatory land-use planning (PLUP) method and the land-use planning and analysis system (LUPAS). Why these? The FAO-MCE uses a semi-quantitative and mechanistic approach. In the FAO guidelines (FAO, 1993) as applied in Vietnam (NIAPP, 1999), the biophysical evaluation and socioeconomic analysis are carried out in ten steps. The multi-criteria evaluation serves to investigate a number of choice-possibilities in the light of multiple criteria and conflicting objectives or development targets. In doing so, it is possible to generate rankings of alternatives according to their attractiveness (Jansen and Rietveld, 1990).

PLUP has gained increasing recognition as an important tool for reaching sustainable resource management by local communities (Amler et al., 1999). PLUP mobilizes local knowledge and resources for self-reliant development and thus reduces the cost to governments for development assistance. People's participation is also recognized as an essential element in strategies for sustain- able agriculture since the rural environment can be protected only with the active collaboration of the local population (FAO, 1991; WB, 1996).

LUPAS is a computerized decision support system for strategic planning based on interactive multiple-goal linear programming (IMGLP) (De Wit et al., 1988). LUPAS uses a set of tools for yield estimation, quantification of input-output relations and optimization of land use at the regional scale under alternative sets of multiple objectives and constraints (van Ittersum et al., 2004; Roetter et al., 2005). LUPAS addresses the questions 'What would be possible?' and 'What has to be changed?' It can be applied for scenario analysis of complex problems such as conflicts in land use (Hoanh et al., 2000). The LUPAS methodology was developed under the Systems Research Network for Eco-regional Land Use Planning in Tropical Asia (SysNet) project (1996-2000). So, LUPAS meets our technological requirements and has also been developed and applied in Asia.

\section{Application of the FAO-MCE Approach}

Figure 14.2 presents what steps were performed in this study. There were eight land mapping units (LMU) in the study area (Fig. 14.1) (NIAPP, 1999). For each LMU, eight land-use types (LUTs) were evaluated. The result of this biophysical land evaluation by NIAPP is shown in Table 14.1.

In the socio-economic and environmental assessment (Fig. 14.2, step 3), secondary data from NIAPP (2001) and data gathered from farm households by a questionnaire are assessed in order to quantify socio-economic and environmental indicators of the land-use systems (LUS). Each indicator is transformed by means of a standardization scheme into a criterion score. The following socio-economic indicators were taken into account: gross income, investment costs, variable costs, total costs, benefit-cost ratio, labour days, environmental impact and financial risk. The environmental assessment was done qualitatively because of a lack of data. The impact of an LUT on the surrounding 
Table 14.1. Land suitability classification after biophysical land evaluation.

\begin{tabular}{lllllll}
\hline LMU & S1 & S1/S2 & S2 & S2/S3 & S3 & N \\
\hline 3 & SR, DR, RV & & RS & & i-e S, s-I S & SS, FS \\
4 & SR, DR, RV & RS & & & i-e S, s-I S & SS, FS \\
16,24 & i-e S & & RS, s-I S & & SR, DR, RV & SS, FS \\
25 & & \multirow{2}{*}{ SS, i-e S, s-I S } & & & SR, DR, RV, SS, FS \\
27,28 & i-e S & i-e S, FS & \multirow{2}{*}{ SS } & i-e S, s-I S & SR, DR, RS \\
29 & FS & & & SS, RS \\
\hline
\end{tabular}

S1, highly suited; S2, moderately suited; S3, marginally suited; N, unsuited; SR, single rice; DR, double rice; RV, rice-vegetable; RS, rice-shrimp; i-e S, improved extensive shrimp; s-I S, semi-intensive shrimp; SS, salt-shrimp; FS, forest-shrimp.

environment is estimated using six indicators, notably sedimentation, salinization, groundwater use, water pollution with organic wastes and nutrients, the use of fertilizer and chemicals, and (irreversible) terrain adjustments. The terrain adjustments are taken into account only for semi-intensive shrimp, improved extensive shrimp and salt. The terrain adjustments needed for the development of these LUTs are the most severe. The degree of environmental impact of each indicator is determined by the results of the farmer interviews, expert knowledge and literature consultation.

The accessibility analysis (Fig. 14.2, step 4) was performed using the 'Accessibility Analyst' extension of the ArcView software package developed by the International Center for Tropical Agriculture (CIAT). It calculates the travel time (road or, in our case, boat) from any given geographical location to the nearest local market where farmers can sell their products. Farmers can reach the markets within $90 \mathrm{~min}$ from any location. This is thought to be enough to keep the products fresh and makes accessibility no limiting factor for socio-economic development.

Figure 14.2, step 5 - generation of land-use scenarios by applying MCE - requires the decision-maker to formulate development targets for which the LUTs are to be evaluated. This person decides what socio-economic and environmental indicators affect the development targets and to what degree. Impact weights have to be assigned to the indicators for each development target.

A land-use scenario can be defined on the basis of development targets with their pri- ority weights (e.g. a $25 \%$ priority for economic development and a $75 \%$ priority for environmental conservation) and the weighted linear combination has to be applied to the alternative LUTs. For each LMU, the LUT that has the highest final evaluation score for a given development target can be regarded as the most suited. The generation of land-use scenarios based on socioeconomic and environmental assessments is a trade-off between LUTs: the best is chosen for a given set of priority weights. Table 14.2 presents the priority weighting sets that were applied to the development targets. In this table, both the second and third scenarios put an accent on social security but the second emphasizes job creation (with a high impact weight for the labour day indicator) while the third minimizes financial risk (high impact weight for this indicator).

When a high priority is given to economic development, most of the LMUs are assigned to semi-intensive shrimp (Fig. 14.3, scenario 6). However, the feasibility of this scenario in terms of labour, capital and technology is not well known. When social security has a high priority, most land is assigned to rice-vegetable or single rice. However, according to farmers, the vegetable market is small in the study area. When environmental sustainability gets a high priority, most land is assigned to single rice. Because of the low income from rice, farmers may not accept this scenario. When all targets have the same priority, single rice is the main LUT; forest-shrimp is mainly suitable near the coast, with rice-vegetable and rice-shrimp in the highland area and near canals (Fig. 14.3, scenario 5). 


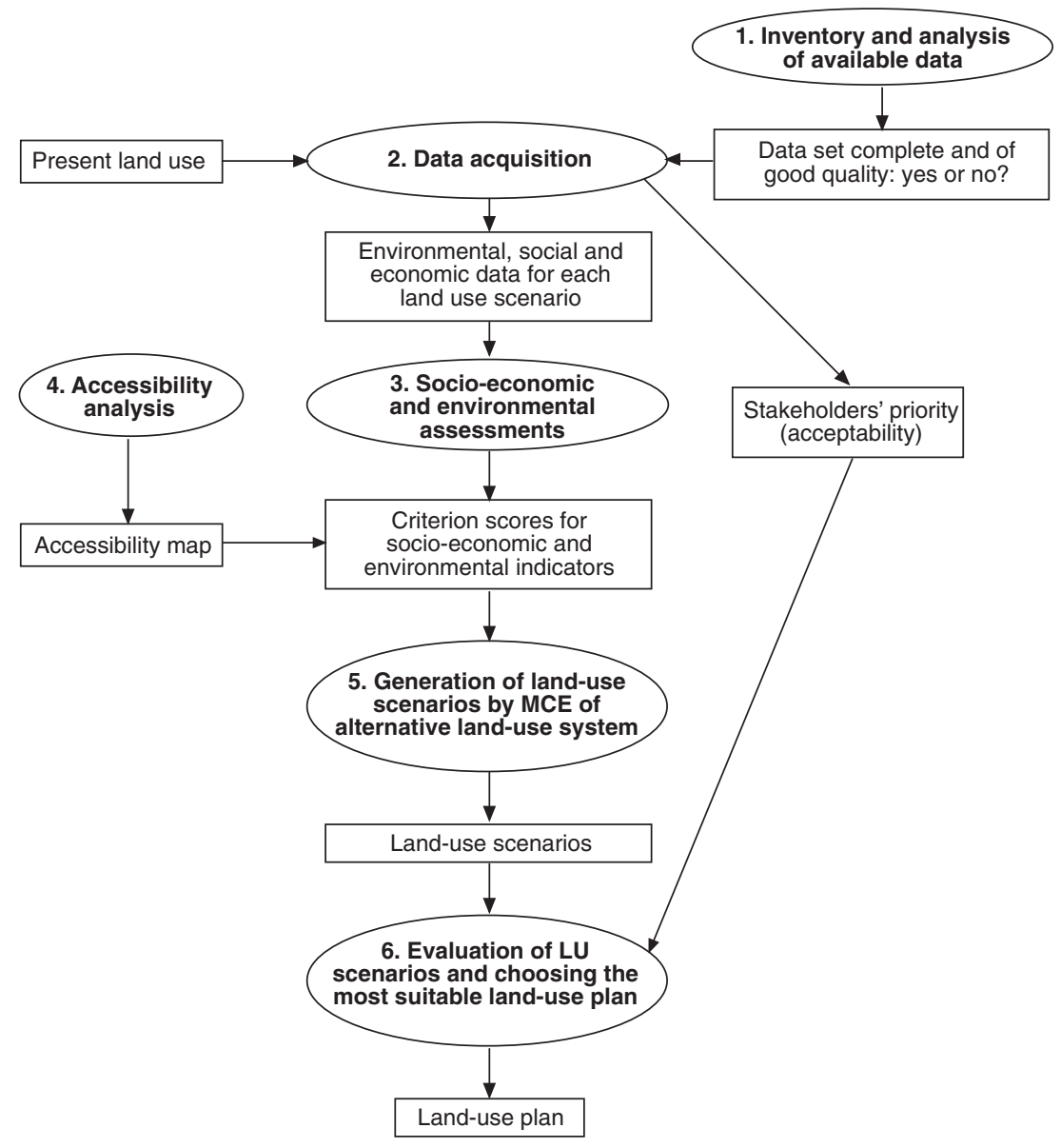

Fig. 14.2. Integrating the FAO approach with MCE (from Kempen, 2004).

The last step is evaluation and selection of the most suitable land-use plan. The evaluation must not only take place on the basis of the development targets but also take into account the wishes and needs of the involved farmers and communities. The final decision must be a compromise between topdown and bottom-up approaches to satisfy the needs of both government and participating stakeholders, communities and municipalities.

Figure 14.3 also presents a proposed LUP based on land-use scenario analysis. The proposed LUP gives priority to economic development while attempting to reduce environmental and financial risk. Shrimp farms should be located close to a canal for proper access to a saltwater source. Rice-shrimp is a safer alternative in the north of the study area, close to the Quan Lo Phung Hiep salinity protection area. The reason is that polluted water from the water control activities may make single-shrimp cultivation risky (Kempen, 2004).

\section{Application of the PLUP Approach}

A modified participatory rural appraisal (PRA) was used based on the toolbox designed by Ticheler et al. (2000) and on experiences from an earlier study in the same area by Feitsma et al. (2002). We took care to avoid their difficulties regarding com- 
Table 14.2. Twelve scenarios with weight sets for the development targets (FAO-MCE approach).

\begin{tabular}{rccc}
\hline Scenario & $\begin{array}{c}\text { Economic } \\
\text { development }\end{array}$ & $\begin{array}{c}\text { Social } \\
\text { security }\end{array}$ & $\begin{array}{c}\text { Environmental } \\
\text { sustainability }\end{array}$ \\
\hline 1 & 1.0 & 0 & 0 \\
2 & 0 & 1.0 & 0 \\
3 & 0 & 1.0 & 0 \\
4 & 0 & 0 & 1.0 \\
5 & 0.33 & 0.33 & 0.33 \\
6 & 0.75 & 0.25 & 0 \\
7 & 0.25 & 0.75 & 0 \\
8 & 0.25 & 0 & 0.75 \\
9 & 0.75 & 0 & 0.25 \\
10 & 0.60 & 0.20 & 0.20 \\
11 & 0.50 & 0.25 & 0.25 \\
12 & 0.25 & 0.50 & 0.25 \\
\hline
\end{tabular}

munication, lack of secondary data, large and scattered hamlets and limited time. Groups of about ten key informants (experienced farmers) were formed in each hamlet. The PLUP was repeated twice, in 2002 and 2003. To have a thorough set of perspectives, agriculture farmers and aquaculture farmers were grouped separately. In each group, farmers participated in reviewing the hamlet's land-use history, described their land conditions and production systems, explained the reasons for land-use change, defined the socio-economic factors that affect the change decisions, drew a sketch map showing the land use and land constraints of their hamlets and proposed the preferred future land use. Transect walks were also conducted to verify the farmers' resource map. During the transect walk, farmers were asked for information on the land and also the land-use types they practised. We analysed land-use change (actual use compared with use in the previous year), the realization of preferences (actual land use compared with what farmers indicated as their preferred land use during the previous year), the preferred change (what they would hope to do next year) and preferences conflicting with those of neighbours.

Results show that land use in the studied area is very dynamic. Within 1 year, more than half of the studied area (58\%) changed use, mostly from agriculture to aquaculture (Fig. 14.4a). The land-use change in 2003 was more than could be expected from the preference expressed by both agriculture and aquaculture farmers in 2002. Half of the preferences were realized, mostly in aquaculture (Fig. 14.4b). In the areas where plans could not be realized, aquaculture or mixed agriculture-aquaculture was practised instead of the preferred agriculture. In other locations, aquaculture was also practised instead of the preferred combination of agriculture-aquaculture.

The major change in farmers' preference was the increased preference for aquaculture at the expense of agriculture (Fig. 14.4c). While in 2002 the farmers' preference for agriculture covered $27 \%$ of the area, in 2003 this was only $4 \%$. The preference change from agriculture to aquaculture or to mixed agriculture-aquaculture was about $23.6 \%$ of the total area. The preference change from mixed agriculture-aquaculture to mono aquaculture covered $17.6 \%$ of the area. The main reasons for those changes were that aquaculture has a higher profit than rice, and that increasing saltwater intrusion due to the expansion of aquaculture forces farmers to plan for aquaculture as other agricultural practices become virtually impossible because of the lack of fresh water (Kempen, 2004). Moreover, according to the adjustment plan for the coastal areas of Bac Lieu, the government was advised to invest in dredging existing canals and excavating new canals for aquaculture development (NIAPP, 2001).

Conflicts in preference were analysed in seven hamlets with both agriculture and aquaculture groups. The 2003 preference maps of both groups were overlaid to delineate the areas of preference conflict. The difference in preference was classified into five levels (Fig. 14.4d): (i) same land-use preference; (ii) partly different preference based on natural conditions; (iii) partly different preference based on economic considerations; (iv) completely different preference based on natural conditions; and (v) completely different preference based on economic considerations. In most of the cases, the aquaculture groups wanted to convert part of the agricultural land into shrimp land while the agriculture groups wanted to continue 
(a)

Scenario 5

Economic: 0.33

Social: 0.33

Environmental: 0.33

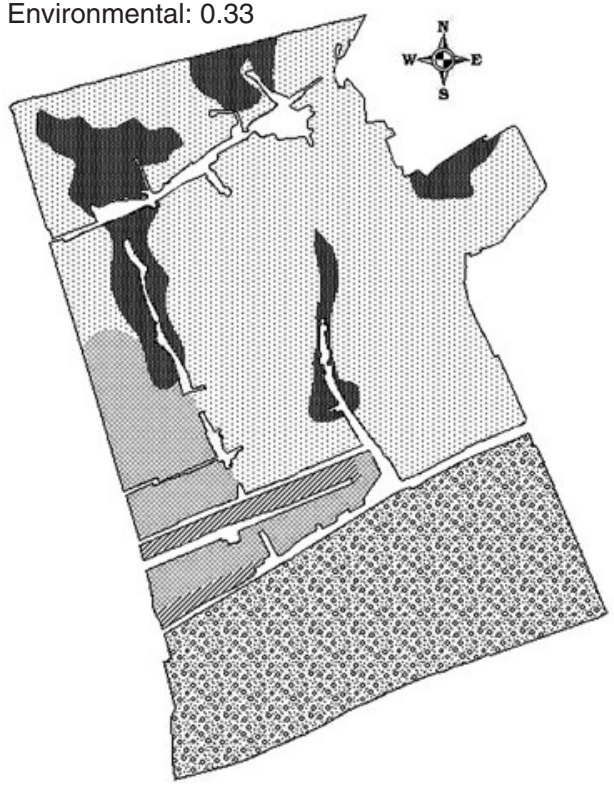

6: Forest-shrimp

W//, Improved extensive shrimp (b)

Scenario 6

Economic: 0.75

Social: 0.25
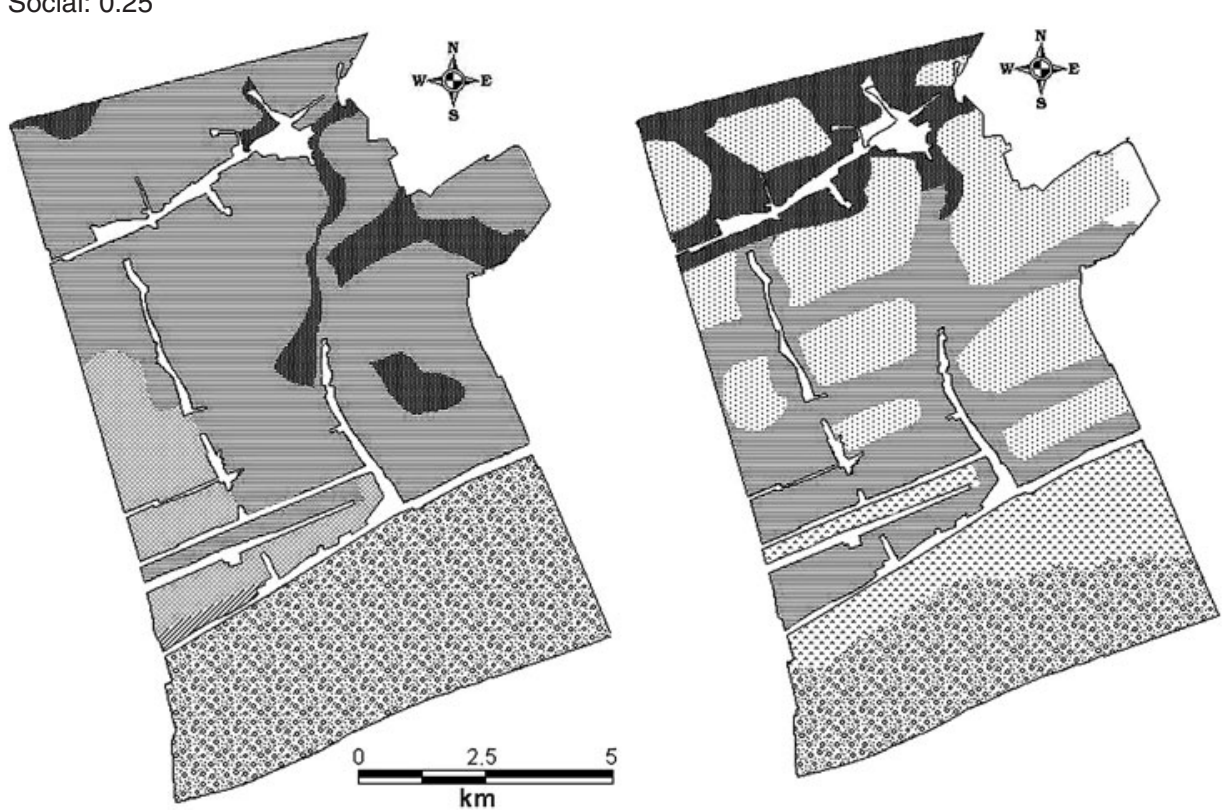

Semi-intensive shrimp, intensive shrimp, salt

Single rice

Rice-vegetable (c)

The proposed land-use plan

Fig. 14.3. Land-use scenario 5 (same priority for all development targets), scenario 6 (higher priority for economic development) and the proposed land-use plan (from Kempen, 2004) 
(a)
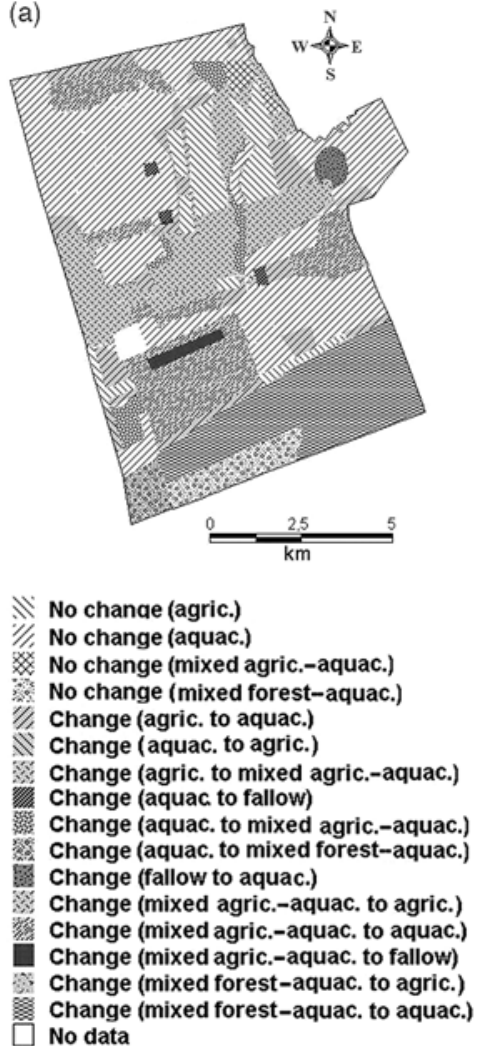

(b)

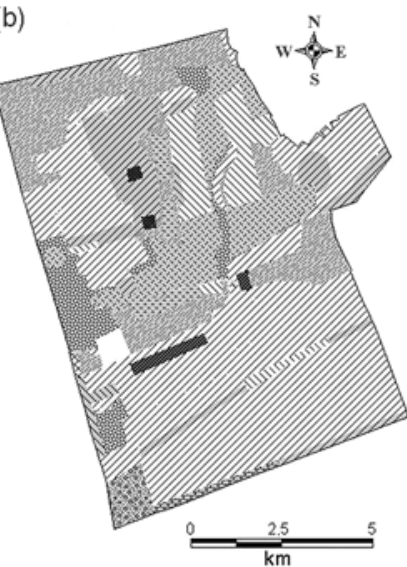

Realized (agric.)

Realized (aquac.)

Realized (mixed agric.-aquac.)

Not realized (aquac. to agric.)

Not realized (agric. to aquac.)

Not realized (agric. to mixed agric.-aquac.)

Not realized (agric. to mixed forest-aquac.)

Not realized (aquac, to mixed agric.-aquac.)

Not realized (aquac. to mixed forest-aquac.)

Not realized (aquac. to mixed forest-aquac.)
Not realized (mixed agric.-aquac. to agric.)

Not realized (mixed agric.-aquac. to agric.)
Not realized (mixed agric.-aquac. to aquac.)

Not realized (aquac. to fallow)

Not realized (agric. to fallow)

No data

(c)

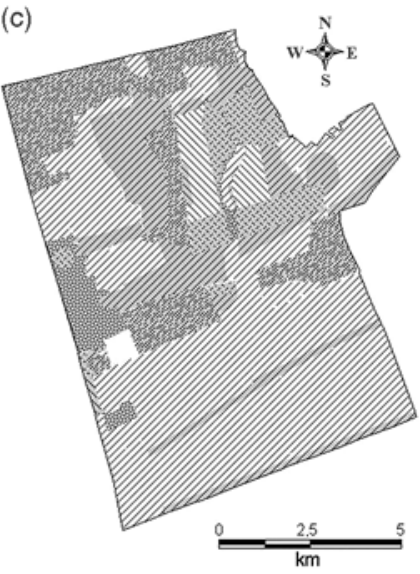

(d)
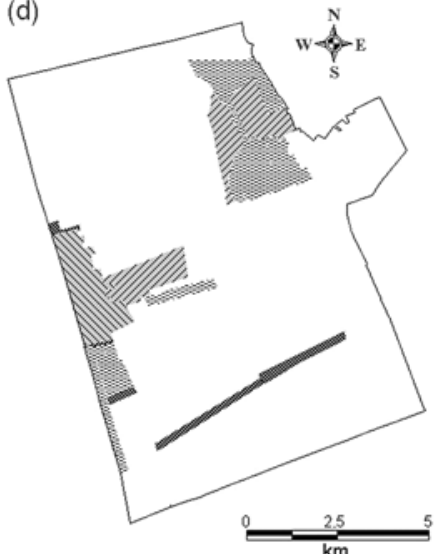

Completely different preference based on (i)

Completely different preference based on (ii)

Partly different preference based on (i)

Partly different preference based on (ii)

Same land-use preference

No change (agric.)

Same land-

\section{No change (aquac.)}

$\square$ No data

(i) economic consideration;

Change (agric. to aquac.

Change (aquac. to agric.)

Change (agric. to mixed agric.-aquac.

Change (aquac. to mixed agric.-aquac.)

Change (mixed agric-aquac. to agric.)

Change (mixed agric.-aquac. to aquac.)

Fig. 14.4. (a) Land-use change 2002-2003; (b) realization of the farmers' preferences in 2002 to the actual land use in 2003, (c) preference change 2002-2003, and (d) preference conflict in 2003. 
cultivating their crops. The agriculture groups either lacked capital and knowledge of aquaculture or believed that rice and vegetables were less risky and still profitable.

\section{Application of the LUPAS Approach}

The structure of LUPAS is illustrated in Fig. 14.5a and consists of a resource balance and land evaluation, a yield estimation, an input-output estimation and an interactive multiple-goal linear programming (IMGLP) part (van Ittersum et al., 2004).

\section{Resource balance and land evaluation}

Similar resource requirements create competition between LUTs. It is critical to determine the resource availability and subsequently the potential or limits of production (Ismail et al., 2000). In LUPAS, the studied area is divided into land units (LU), unique combinations of an agro-ecological and an administrative unit. The LU map is used for spatial display as well as for the IMGLP. In this study, the LMUs of NIAPP $(1999,2001)$ are overlain with the village boundary map, resulting in 30 LUs.

Eleven promising LUTs considered in this study were single rice, rice-vegetable, vegetable, extensive shrimp, modified extensive shrimp, semi-intensive shrimp, salt, salt-shrimp, forest-shrimp, rice-shrimp and mangrove forest.

Resource needs such as labour, capital, land and water were assessed. Available land for production (10,700 ha) was determined by excluding built-up and protected areas. Available labour was based on the total population, 17,700 in Vinh My and 10,480 in Vinh Thinh (NIAPP, 1999). Tri et al. (2002) claim that $60 \%$ of the population in the study area is between 18 and 60 years old. We observed many labourers under 17 and from adjacent villages. Because data on capital used are not available, they were estimated from the current input cost for actual land use plus available credit.

\section{Yield and input-output estimation}

The main tools and techniques used for input-output and yield estimation are crop yield simulation or statistical models, expert judgement and farm surveys (Hoanh et al., 2000). Input-output is described by total input cost, labour requirement and revenue of each promising LUT per LU. In this study, yield and input-output of LUTs are determined at the current technical level and at an improved technical level. These levels are based on recent average and recent maximum values from a field survey or previous studies.

\section{Interactive, multiple-goal linear programming}

Based on existing land-use planning (NIAPP, 1999), annual development strategy documents and actual land use, objectives and goal restrictions are distinguished. They are to maximize the total regional income from agriculture and aquaculture products, to realize the strategic rice, shrimp, salt and vegetable production quotas and to protect the mangrove forest. Since our objective is to compare LUPAS with PLUP and the FAOMCE, the case study was narrowed to maximizing the total income in two scenarios: (i) all farmers apply the actual technical level (this refers to the production techniques currently practised by the majority of the farmers in the studied area); and (ii) all farmers apply an improved technical level that refers to a higher level of production, the 'attainable yield' (Tawang et al., 2000), by advanced farmers in the study area.

The study area had the following resource constraints and goal restrictions:

- The total area of all LUTs allocated in an LU must be less than or equal to the total area available of that LU;

- The total labour needed for all planned production activities in a village must be less than or equal to the labour available in that village;

- The total capital need for the allocated LUTs in an LU must be less than or equal to the total available capital of that LU; 


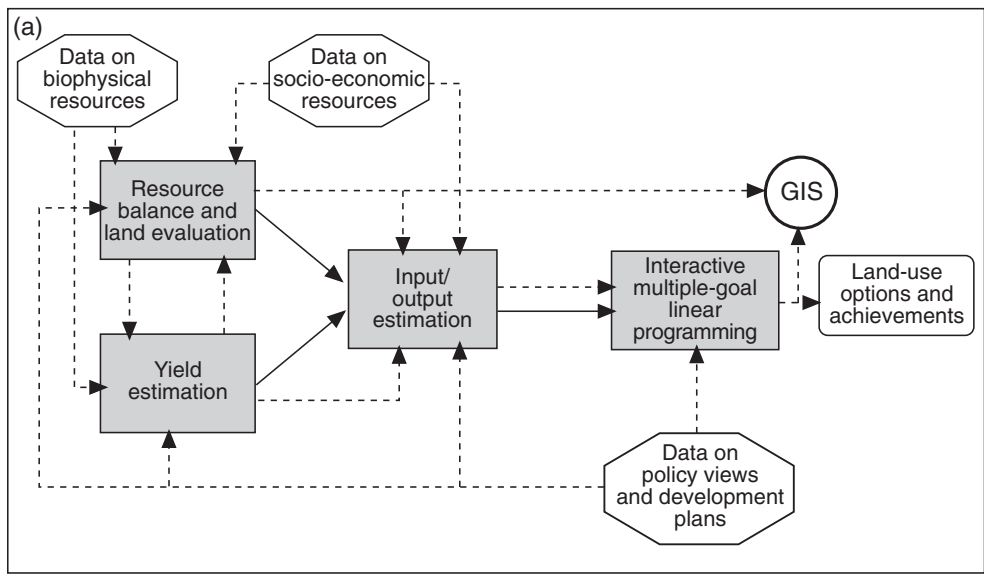

(b)

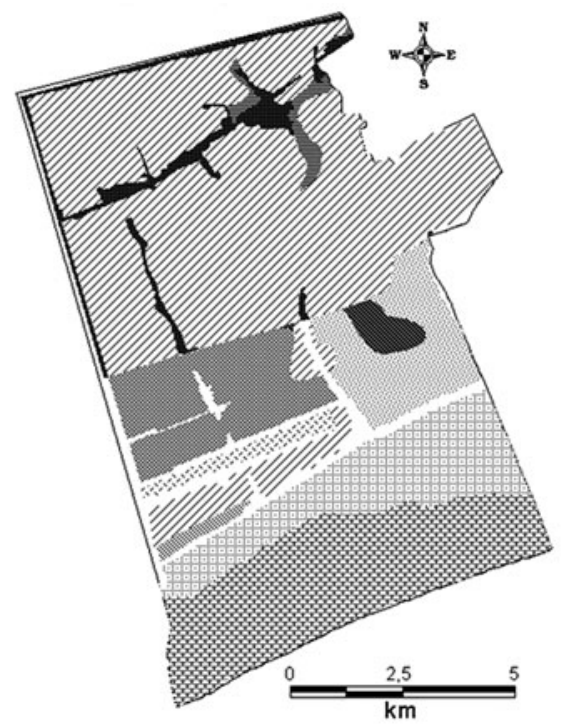

Forest, forest-shrimp
Modified ext. shrimp

Modified ext. shrimp, semi-int. shrimp, salt-shrimp

Rice, modified ext shrimp

Rice, modified ext. shrimp, se

Rice-shrimp

Salt-shrimp

Semi-int. shrimp

Semi-int. shrimp, salt-shrimp Vegetables

Fig. 14.5. (a) Components of LUPAS (from Roetter et al., 2000) and (b) land-use planning for scenario 9 (with rice, vegetable, salt and forest goals) at current technical level. 
- The total rice, shrimp, salt and vegetable production of the study area must be greater than or equal to the rice, shrimp, salt and vegetable production required/ targeted by the local government; and

- The total mangrove forest areas allocated in the study area must be greater than or equal to the mangrove forest area targeted by the local government.

A LUPAS model for the case study was developed using the GAMS software (GAMS Development Corporation, <http://www. gams.com>). Table 14.3 shows the results of the nine feasible scenarios based on combinations of objectives with sets of constraints and/or goal restrictions. The first scenario represents the most favourable conditions, when only biophysical suitability of the land and the land area constraint apply. It generates the potential biophysical production, which is hard to achieve. However, it can be used to evaluate the potential income from agriculture and aquaculture under the actual biophysical conditions. The subsequent scenarios demonstrate what constraints and goal restrictions affect the overall goal most, so that the tradeoffs between goals can be analysed and a more feasible and sustainable land-use plan made. that:

In general, the results (Table 14.3) imply

- For maximizing the total income of the study area, the model assigns a high proportion of land area to shrimp LUTs. This is very risky in case a drop in shrimp yield is experienced;

- Twice the income can be achieved by improving cultivation technology to the existing maximum level;

- Capital and cultivation techniques are the main constraints. Labour problems can be solved by using machines, especially in land preparation and harvesting; and

- Goal restrictions (upper limit of production targets) slightly affect the total income but strongly influence land allocation. Thus, by changing goal restrictions, the risk can be reduced, for example, reducing the shrimp production target.

Figure $14.5 \mathrm{~b}$ presents the land-use planning resulting from scenario 9 when targets of rice, vegetable, salt and forest area requirement were taken into account at the present technical level.

\section{Comparing the Three LUP Approaches}

We used acceptability (agreement of stakeholders with the results and requirements of the three methods) and credibility (prediction quality and uncertainty of the plans) as criteria to compare the LUP approaches. The acceptability and credibility criteria were derived from a framework presented by van der Molen (1999).

\section{Acceptability}

The agreement was prepared by asking 25 stakeholders their opinion (agree, partly agree, disagree) on the three LUP maps for 2004 that had resulted from our approaches. They had no prior knowledge of which method produced which map: results are in Table 14.4. The stakeholders are managers (provincial and district politicians), local experts (staff of extension services) and scientists (university staff and researchers in LUP). LUPAS scores best, with $21 / 25$ partly agreeing and $4 / 25$ fully agreeing with the LUPAS plan. Most answered partly because they feared insufficient provision of fresh water for rice and rice-shrimp. Few people fully agree with FAO-MCE and PLUP but far more people disagree with these plans than with the LUPAS plan. The reasons for this are expected insurmountable problems for adequate irrigation (both plans) and far too scattered land allocation (PLUP). The three groups judge LUPAS similarly (and most favourably) but local experts judge PLUP higher than the managers and scientists. In general, the results suggest that the perception of the local experts and local managers is somewhat closer to the farmers' perception than that of the scientists

In terms of resources required for implementation of LUP methods, PLUP is much cheaper (4640 VN dong/ha) than FAO-MCE $(20,650)$ and LUPAS $(24,000)$. PLUP takes the most time and person-months but it requires 
Table 14.3. Results of maximizing income at actual technical level (LUPAS approach).

\begin{tabular}{|c|c|c|c|c|c|c|c|c|c|}
\hline \multirow{2}{*}{$\begin{array}{l}\text { Constraints } \\
\text { and targets }\end{array}$} & \multirow{2}{*}{$\begin{array}{l}\text { Income } \\
\qquad\left(10^{9}\right. \\
\text { VND })\end{array}$} & \multicolumn{4}{|c|}{ Production (t) } & \multicolumn{2}{|c|}{ Environment } & \multicolumn{2}{|c|}{ Resource used } \\
\hline & & Rice & Shrimp & Salt & Veg. & $\begin{array}{l}\text { Forest } \\
\text { (ha) }\end{array}$ & $\begin{array}{l}\text { Land } \\
(\%)\end{array}$ & $\begin{array}{c}\text { Capital } \\
\left(10^{9}\right. \\
\text { VND })\end{array}$ & $\begin{array}{l}\text { Labour } \\
\qquad\left(10^{6}\right. \\
\text { days })\end{array}$ \\
\hline Land & 1,944 & 351 & 22,611 & 4,296 & 15,115 & 1,096 & 100 & 1,241 & 1.85 \\
\hline Land, labour & 1,694 & 1,474 & 20,485 & 11,295 & 7,208 & 1,050 & 84 & 1,188 & 1.39 \\
\hline Land, capital & 1,111 & 351 & 9,123 & 4,296 & 15,115 & 1,096 & 87 & 186 & 1.41 \\
\hline Land, labour, capital & 974 & 738 & 8,025 & 30,390 & 15,115 & 1,096 & 83 & 178 & 1.29 \\
\hline $\begin{array}{l}\text { Land, labour, capital, } \\
\text { rice }\end{array}$ & 972 & 2,940 & 7,990 & 27,678 & 15,115 & 1,096 & 86 & 177 & 1.29 \\
\hline $\begin{array}{l}\text { Land, labour, capital, } \\
\text { salt }\end{array}$ & 974 & 738 & 8,025 & 30,390 & 15,115 & 1,096 & 83 & 178 & 1.29 \\
\hline $\begin{array}{l}\text { Land, labour, capital, } \\
\text { vegetable }\end{array}$ & 969 & 738 & 8,071 & 28,821 & 3,000 & 1,096 & 76 & 174 & 1.17 \\
\hline $\begin{array}{l}\text { Land, labour, capital, } \\
\text { rice, vegetable }\end{array}$ & 968 & 2,940 & 8,045 & 28,105 & 3,000 & 1,096 & 80 & 175 & 1.18 \\
\hline $\begin{array}{l}\text { Land, labour, capital, } \\
\text { rice, vegetable, salt, } \\
\text { forest }\end{array}$ & 930 & 2,940 & 7,845 & 16,000 & 3,000 & 1,360 & 81 & 181 & 1.10 \\
\hline
\end{tabular}

VND, Vietnamese dong.

Table 14.4. Stakeholders' opinions on land-use plans generated by LUPAS, FAO-MCE and PLUP.

\begin{tabular}{llccr}
\hline \multirow{2}{*}{ Group } & Agreement & \multicolumn{3}{c}{ Number of stakeholders } \\
\cline { 3 - 5 } & & LUPAS & FAO-MCE & PLUP \\
\hline \multirow{2}{*}{ Managers (9) } & Agree & 2 & 3 & 0 \\
& Partly agree & 7 & 2 & 5 \\
& Disagree & 0 & 4 & 4 \\
Local experts (9) & Agree & 1 & 1 & 3 \\
& Partly agree & 8 & 4 & 2 \\
\multirow{5}{*}{ Scientists (7) } & Disagree & 0 & 4 & 4 \\
& Agree & 1 & 0 & 0 \\
All (25) & Partly agree & 6 & 2 & 2 \\
& Disagree & 0 & 5 & 5 \\
& Agree & 4 & 4 & 9 \\
& Partly agree & 21 & 13 & 13 \\
\hline
\end{tabular}

only simple software (statistics, GIS) for analysis. FAO-MCE requires modelling and statistics skills, whereas, for LUPAS, specialized training and much more expert time for analysis are needed.

\section{Credibility}

We compared the land-use plans made in 2003 with the actual land use of 2004. PLUP looks most like the actual use $(75 \%$ of the surface agrees) and next are LUPAS (62\%) and FAO-MCE (33\%). The areas planned for aquaculture agreed best $(96 \%, 96 \%$ and $76 \%$ of the planned area actually had aquaculture the next year). For agriculture (rice, vegetables), FAO-MCE agreed best but this is because in this plan a much larger area was reserved for these activities than in the other two plans. In all three plans, the areas that did not agree were largely mixed systems of 
(a)

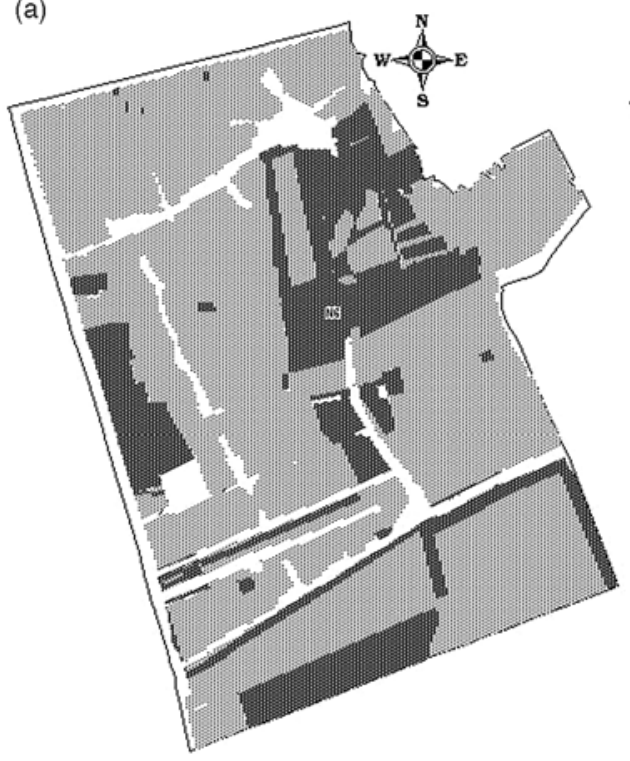

(b)

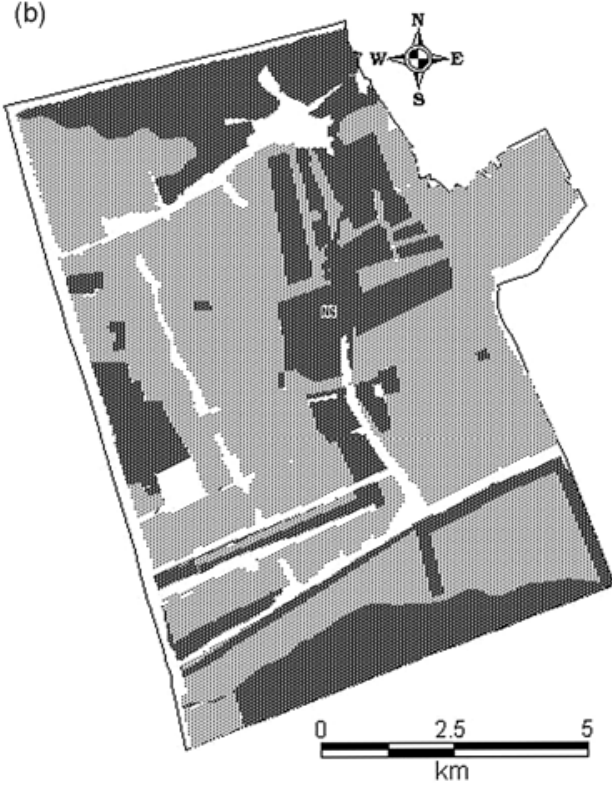

(c)

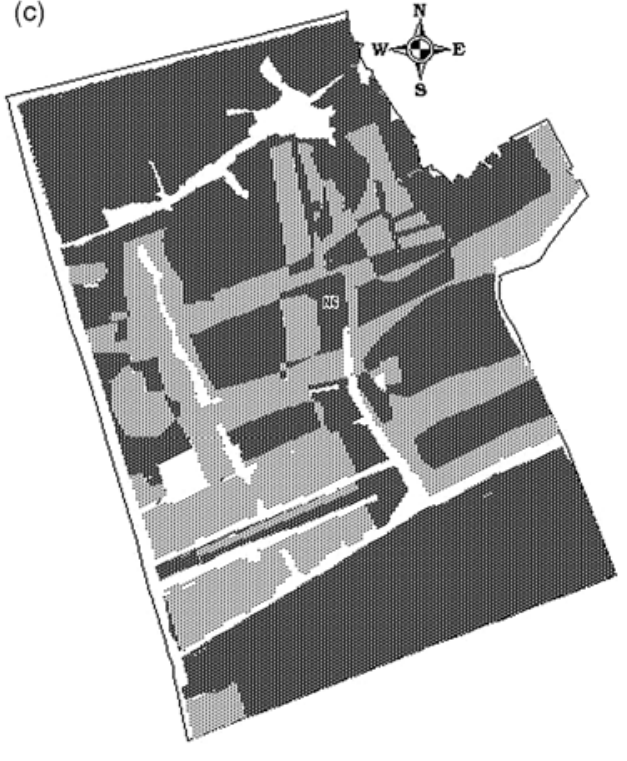

Not realized $\quad$ IIIII Realized $\quad \square$ Built-up areas or no data

Fig. 14.6. Realization of land-use plans for 2004 of (a) PLUP, (b) LUPAS and (c) FAO-MCE approaches. 
rice-shrimp, vegetable-rice or forest-shrimp. In most cases, farmers preferred to go for one crop only, aquaculture, as this one is far more profitable than the other planned activities. So, most mixed systems turned into single aquaculture. Figure 14.6 shows where the plans were realized and where not. Areas where plans were not realized are along the coast (the planned mixed forest-shrimp was turned into shrimp only by the farmers) and in the central-northeastern part, where planned single rice and mixed rice-shrimp turned mostly into single aquaculture.

\section{Discussion and Conclusions}

The LUPAS map is the most accepted by managers, scientists and local experts. While scientists do not agree with either the FAOMCE or the PLUP maps, the proportion of local experts and local managers that fully or partly agree with PLUP is higher than with FAO-MCE.

When comparing land-use plans made in 2003 with the actual land use in 2004, the PLUP map, which is disagreed with most strongly by the scientists, is the most realized. The reason for this may be that the PLUP map, drawn by the farmers, is based on actual land use and for the short term, whereas the other approaches aim at optimized resource use and the long term.
In PLUP, the attitude of the key farmers and the skill of the discussion facilitator during the PRA are the most important factors. In the FAO-MCE approach, it is crucial to detect the right key indicators for each discipline, qualify them and determine their importance. Land evaluation studies supply the input for both LUPAS and FAO-MCE approaches. However, their static description of biophysical conditions seems unsuitable for describing the rapid changes in the coastal area as explained above. Accurate transfer of the socio-economic characteristics of the study area into the model and obtaining precise data on production systems are challenges when applying both LUPAS and FAO-MCE in the coastal area of the MD.

The analysis shows that with dynamic and contrasting land uses, as in the coastal zone of the MD, PLUP seems the most suitable approach since it is capable of acquiring up-to-date information on actual land conditions and of presenting the farmers' land-use preference. In PLUP, the places and causes of land-use conflicts can be defined. This can help land-use planners in finding solutions to achieve an acceptable land-use plan. However, for a sustainable land-use plan over a longer term that can optimize the use of resources and balance different stakeholders' priorities, these LUP approaches should be integrated.

\section{References}

Amler, B., Betke, D., Eger, H., Ehrich, C., Hoesle, U., Kohler, A., Kösel, C., Lossau, A.V., Lutz, W., Müller, U., Schwedersky, T., Seidemann, S., Siebert, M., Trux, A. and Zimmermann, W. (1999) Land Use Planning Methods, Strategies and Tools. GTZ, Berlin.

De Wit, C.T., Vankeulen, H., Seligman, N.G. and Spharim, I. (1988) Application of interactive multiplegoal programming techniques for analysis and planning of regional agricultural development. Agricultural Systems 26, 211-230.

FAO (1991) Plan of action for people's participation in rural development. FAO Conference Sessions 26, Rome, p. 19.

FAO (1993) Guidelines for land-use planning. FAO Development Series 1, FAO, Rome, p. 96.

Feitsma, M., Vincent, L. and Can, N.D. (2002) Understanding the challenges of PRA for farming systems research: lessons from coastal Vietnam. In: Van Mensvoort, M.E.F. and Tri, L.Q. (eds) Selected Papers of the Workshop on Integrated Management of Coastal Resources in the Mekong Delta, Vietnam. C.T. de Wit Graduate School for Production Ecology \& Resource Conservation (PE \& RC), Wageningen, Netherlands.

Hoanh, C.T. (1996) Development of a computerized aid to integrated land use planning (CAILUP) at regional level in irrigated areas: a case study for the Quan Lo Phung Hiep region in the Mekong Delta, Vietnam. PhD thesis, Wageningen University, Wageningen, Netherlands. 
Hoanh, C.T., Roetter, R.P., Aggarwal, P.K., Bakar, I.A., Tawang, A., Lansigan, F.P., Francisco, S., Lai, N.X. and Laborte, A.G. (2000) LUPAS: an operational system for land use scenario analysis. In: Roetter, R.P. et al. (eds) Systems Research for Optimizing Future Land Use in South and South-east Asia. SysNet Research Paper Series No. 2, International Rice Research Institute, Los Baños, Philippines, pp. 39-53.

Ismail, A.B., Ahmad Shokri, O., Laborte, A.G., Aggarwal, P.K., Lansigan, F.P. and Lai, N.X. (2000) Methodologies for resource balancing and land evaluation as applied in the SysNet case studies. In: Roetter, R.P. et al. (eds) Systems Research for Optimizing Future Land Use in South and South-east Asia. SysNet Research Paper Series No. 2, International Rice Research Institute, Los Baños, Philippines, pp. 121-131.

Jansen, R. and Rietveld, P. (1990) Multicriteria analysis and GIS: an application to agricultural use in the Netherlands. In: Geographic Information System for Urban and Regional Planning. Kluwer Publishers, Dordrecht, Netherlands.

Kempen, B. (2004) Multi-criteria evaluation as a decision-making tool in land use planning on district level: integrating biophysical land evaluation with socio-economic and environmental assessments in a decision support system for land use planning, with applications for the coastal zone of Vinh Loi district, Mekong Delta, Vietnam. MSc thesis, Wageningen University and Research Center, Wageningen, Netherlands.

NIAPP (1999) Report on Land Evaluation for Agriculture, Forestry and Fishery in Bac Lieu Province [in Vietnamese]. National Institute of Agriculture Planning and Projection, Vietnam.

NIAPP (2001) Adjustment Plan for Agriculture, Aquaculture, Salt and Forest Production in South of National Road 1A, Bac Lieu Province [in Vietnamese]. Ho Chi Minh City, Vietnam.

Roetter, R.P., Keulen, H.V., Laborte, A.G., Hoanh, C.T. and Laar, H.H.V. (eds) (2000) Systems Research for Optimizing Future Land Use in South and South-east Asia. SysNet Research Paper Series No. 2, International Rice Research Institute, Los Baños, Philippines, 266 pp.

Roetter, R.P., Hoanh, C.T., Laborte, A.G., Van Keulen, H., Van Ittersum, M.K., Dreiser, C., Van Diepen, C.A., De Ridder, N. and Van Laar, H.H. (2005) Integration of systems network (SysNet) tools for regional land use scenario analysis in Asia. Environmental Modelling and Software 20, 291-307.

Stoorvogel, J.J. (2001) The Tradeoff Analysis Model Version 3.1: A Policy Decision Support System for Agriculture: User Guide. Wageningen University, Laboratory of Soil Science and Geology, Wageningen, Netherlands.

Tawang, A., Bakar, I.A., Kamaruddin, A.A., Yahya, T.M.T., Abdullah, M.Y., Jaafar, H.B., Othman, A.S., Yusof, A., Ismail, Z., Hamzah, A.R., Jaafar, A.M., Aziz, Z.A., Ghani, M.Z.A., Majid, N.A. and Rashid, A.A. (2000) Developing and appying LUPAS in the Kedah-Perlis Region, Malaysia: methodologies, results and policy implications. In: Roetter, R.P. et al. (eds) Systems Research for Optimizing Future Land Use in South and South-east Asia. SysNet Research Paper Series No. 2, International Rice Research Institute, Los Baños, Philippines, pp. 71-89.

Ticheler, J., Defoer, T. and Kater, L. (2000) ResourceKit for participatory learning and action research. Detailed field tools for PLARUser's guide for the ResourceKIT, CD-ROM Managing Soil Fertility in the Tropics. KIT, Amsterdam, p. 1.

Tri, L.Q., Sanh, N.V., Ha, V.V., Loi, L.T. and Binh, N.S. (2002) Social-economic aspects of farming systems in Vinh Loi, Thanh Phu, and Dam Doi districts, Mekong Delta, Vietnam. In: Van Mensvoort, M.E.F. and Tri, L.Q. (eds) Selected Papers of the Workshop on Integrated Management of Coastal Resources in the Mekong Delta, Vietnam. C.T. de Wit Graduate School for Production Ecology \& Resource Conservation (PE \& RC), Wageningen, Netherlands, pp. 17-27.

van der Molen, D. (1999) The role of eutrophication models in water management. PhD thesis 2626, Wageningen University, Wageningen, Netherlands.

van Ittersum, M.K., Roetter, R.P., van Keulen, H., de Ridder, N., Hoanh, C.T., Laborte, A.G., Aggarwal, P.K., Ismail, A.B., and Tawang, A. (2004) A systems network (SysNet) approach for interactively evaluating strategic land use options at sub-national scale in South and South-east Asia. Land Use Policy 21, 101-113.

Veldkamp, A., and Fresco, L.O. (1996) CLUE: a conceptual model to study the conversion of land use and its effects. Ecological Modelling 85, 253-270.

WB (1996) The World Bank Participation Sourcebook. Environmentally Sustainable Development Publications, World Bank, Washington, DC, 259 pp. 